\title{
Sport-related Dental Trauma and Mouthguard Use among Athletes in Riyadh, Saudi Arabia: A Cross-sectional Survey
}

\author{
Omar A Bawazir ${ }^{1}$, Abdullah I Alqoair², Yahya N Alayed ${ }^{3}$
}

\begin{abstract}
Aim and objective: The present cross-sectional survey was conducted to assess the prevalence and the type of dental injury along with the awareness and use of mouthguards among the athletes of Riyadh, Saudi Arabia.

Materials and methods: This questionnaire-based survey included four major sports clubs in Riyadh city (AlHilal, AINassr, AIShabab, AlRiyadh), Saudi Arabia where 300 questionnaires were distributed. Participants who engaged in direct, indirect, and no/ minimal contact sports such as taekwondo, soccer, and volleyball, respectively were explained about the importance of the study and its significance. The questionnaire was divided into three parts covering the demographic details, sports-related injury, mouthguard awareness, and its use. Data from completely filled questionnaire were collected, tabulated, and analyzed. Descriptive statistics and Pearson Chi-square tests were considered for statistical analysis. Result: A total of 234 athletes (104 football/soccer, 57 volleyball, and 73 taekwondo) participated in the study with a response rate of $78 \%$. Taekwondo and football athletes experienced more dental trauma than volleyball players. Dental trauma was highest in taekwondo (56.2\%), followed by football (52.9\%) and volleyball (31.6\%) athletes. Crown fractures (43.6\%) were the most common dental injury reported followed by mobility (18\%). Taekwondo athletes were better aware regarding mouthguard ( $83.6 \%)$ and used it during practice (43.8\%) when compared to football and volleyball athletes.

Conclusion: It was observed that athletes of direct and indirect contact sports (taekwondo and soccer) were at greater risk of dental trauma thereby emphasizing the importance of prevention strategies. Though a significant proportion of athletes were aware of mouthguard, its types, and its role in the prevention of dental trauma, only a handful of them regularly used it.

Clinical significance: Sport-related dental injuries though prevalent among athletes, measures to curb them are limited. These injuries may directly or indirectly hamper the performance of the player and affect their career. Therefore, combined efforts from dentist, coach, and sport physician are required to educate, enhance awareness, and encourage the use of mouthguards in contact sports.

Keywords: Athletes, Awareness, Dental injuries, Mouthguard, Sports.

World Journal of Dentistry (2022): 10.5005/jp-journals-10015-1897
\end{abstract}

\section{INTRODUCTION}

Sports, in particular, contact sports are one of the prime etiological factors for trauma. Knocks, strikes, dives, and hard surface contacts are frequent occurrences in sport activities. Translation of these risk factors to orofacial trauma are equally chronic in nature. Literature documents trauma to be the causative factor for nearly $19 \%$ head and face injuries and $33 \%$ of dental injuries. ${ }^{1}$ Majority of these injuries are responsible for irreversible dental loss, ankyloses, or root resorption suggestive of treatment failures irrespective of management. ${ }^{2}$ The vulnerable position of the maxillary jaw and teeth labels it as the prone site to sustain oromaxillofacial injury with crown fractures dominating the dental sports injury. 3,4

Contact sports are characterized by physical interaction between players striving to win against opposing member or team where the force and occurrence of contact may be the significant factor for dental trauma. Based on the form of contact, sports can be categorized as direct (taekwondo, kick boxing, boxing, etc.), indirect (handball, basketball, football/soccer), and no/minimal contact (volleyball, badminton) sports. ${ }^{5}$ Depending on the type of sport, prevalence of dental trauma ranges from 8 to $45 \%$ as reported by different studies. Volleyball, a no/minimal contact sport reports comparatively a reduced prevalence of dental injury than direct contact taekwondo sport (38.6\%). ${ }^{6}$ In soccer, irrespective of being an indirect contact sport, it exhibits high risk of injuries owing to the outline of the game where head is frequently used to score,
${ }^{1}$ Department of Pediatric Dentistry and Orthodontics, College of Dentistry, King Saud University, Riyadh, Saudi Arabia

${ }^{2,3}$ Ministry of Health, Riyadh, Saudi Arabia

Corresponding Author: Omar A Bawazir, Department of Pediatric Dentistry and Orthodontics, College of Dentistry, King Saud University, Riyadh, Saudi Arabia, Phone: +966505755898, e-mail: obawazir@ksu. edu.sa

How to cite this article: Bawazir OA, Alqoair Al, Alayed YN. Sport-related Dental Trauma and Mouthguard Use among Athletes in Riyadh, Saudi Arabia: A Cross-sectional Survey. World J Dent 2022;13(1):21-25.

Source of support: Nil

Conflict of interest: None

pass, and defend thereby responsible for possible craniofacial and dental injuries due to the impact encountered. ${ }^{7,8}$

Mouthguards are considered as the most effective and efficient method to prevent dental injuries. ${ }^{9,10}$ They are available as (1) stock mouthguards which are prefabricated in different sizes; (2) boil and bite mouthguard, fabricated from thermoplastic material which when immersed in hot water takes the form in athlete's mouth; and (3) dentist-fabricated custom-made mouthguards. ${ }^{11,12}$

On examination of 862 Saudi Arabian boys aged 12 to 14 years, a study reported them to have endured at least one dental trauma to permanent maxillary incisors. Enamel fracture ranked the highest dental injury with a prevalence of $9.7 \%$ of 3,441 evaluated 
teeth while dentin fracture with pupal involvement was observed in $0.6 \%$ of teeth assessed, of which $0.3 \%$ incisors were lost due to trauma. ${ }^{13}$ Limited studies are available on dental trauma in athletes in Saudi Arabia. Further the awareness and the utilization of mouthguard, an important aid to prevent dental injuries also presents with a dearth of studies. Therefore, the present study aimed to assess the prevalence and the type of dental injury along with the awareness and use of mouthguard among the athletes of Riyadh, Saudi Arabia.

\section{Materials and Methods}

This cross-sectional survey was conducted from January to April 2016 which included four major sports clubs of Riyadh city namely: AlHilal SFC, AINassr FC, AIShabab FC, and AIRiyadh SC. Ethical approval was obtained from College of Dentistry Research Center, King Saud University, Riyadh for the study. Sportspersons who were members of the above clubs practicing taekwondo, football/soccer, and volleyball representing direct, indirect, and no contact sports, respectively and who belonged to either the Professional or Olympic league teams were approached for the study. Sportspersons who do not represent the above categories or those who do not provide their consent for the study were not considered.

The participants who satisfied the selection criteria were informed about the study and its significance. Those who were interested were requested to fill the consent form of participation followed by the study questionnaire. The questionnaires were later collected from the principal in-charge of the respective clubs and only those that were completely filled were considered for evaluation.

The questionnaire prepared was an amalgamation of questions addressed in similar studies in different populations. ${ }^{14-17}$ They were read, analyzed, and modified to accommodate the present study environment and translated to Arabic language. The questionnaire consisted of 14 questions, divided into 3 parts that aimed to address the following: (1) questions pertaining to the demographic data and the sport practiced; (2) questions related to past history of sports-related dental injury; and (3) questions with reference to awareness, knowledge, and the use of mouthguard.

The data collected were analyzed using the Statistical Package for Social Sciences (IBM SPSS Statistic version 21). Descriptive statistics and Pearson Chi-square were used to observe the association between the categorical study and outcome variables. $p$ value of $<0.05$ was considered to be statistically significant.

\section{Result}

A total of 300 questionnaires were distributed among the four major sports clubs in Riyadh city, of which only 234 were completely filled and returned. The response rate obtained was $78 \%$. Out of 234 athletes, 104 (44.4\%) football/soccer, 73 (31.2\%) taekwondo, and $57(24.40 \%)$ volleyball sportsperson participated in the study. The mean age of athletes of football/soccer, volleyball, and taekwondo were $22.7 \pm 4.3,25 \pm 5.9$, and $22.9 \pm 4.5$ years, respectively. Majority (49.1\%) of athletes were high school graduates. On observation, most of the athletes (31.6\%) were playing their respective sports for more than 9 years, while the time duration reserved for practicing by majority (88\%) of them was less than 5 hours daily (Table 1).

Awareness of the probability of dental injury was highly prevalent among the participants: $83.6 \%, 81.7 \%$, and $84.2 \%$ of taekwondo, football/soccer, and volleyball players, respectively were well informed and knowledgeable about the possibility of the dental injuries associated with their sports. It was observed that $56.2 \%$ of taekwondo and $52.9 \%$ of football players, the direct and indirect contact sports, respectively reported an increased experience of dental trauma when compared to $31.6 \%$ of volleyball players. Also, it was noted that statistically insignificant difference was established between football/soccer and taekwondo athletes ( $p=0.056$ ): $60.3 \%$ taekwondo and $56.7 \%$ football/soccer athletes reported significant prevalence of maxillofacial injuries when compared to $26.3 \%$ volleyball players $(p<0.0001)$. Overall, crown fractures $(43.6 \%)$ followed by tooth

Table 1: Sociodemographic variables of study subjects

\begin{tabular}{|c|c|c|c|}
\hline \multirow[b]{2}{*}{ Variables } & \multicolumn{3}{|c|}{ Type of sport } \\
\hline & $\begin{array}{c}\text { Football } \\
(n=104) \\
n(\%)\end{array}$ & $\begin{array}{c}\text { Volleyball } \\
\begin{array}{c}(n=57) \\
n(\%)\end{array}\end{array}$ & $\begin{array}{c}\text { Taekwondo } \\
\begin{array}{c}(n=73) \\
n(\%)\end{array}\end{array}$ \\
\hline Age in years (mean and standard deviation) & $22.7(4.3)$ & $25(5.9)$ & $22.98(4.5)$ \\
\hline \multicolumn{4}{|l|}{ Education level $(n=234)$} \\
\hline Primary & $4(3.8)$ & 0 & $1(1.4)$ \\
\hline Elementary & $11(10.6)$ & $4(7.0)$ & $5(6.9)$ \\
\hline High school & $39(37.5)$ & $31(54.4)$ & $45(61.6)$ \\
\hline Bachelor & $50(48.1)$ & $22(38.6)$ & $22(30.1)$ \\
\hline \multicolumn{4}{|l|}{ Time duration playing sport $(n=234)$} \\
\hline$<3$ years & $9(8.6)$ & $19(33.3)$ & $8(11)$ \\
\hline $3-6$ years & $32(30.8)$ & $14(24.6)$ & $23(31.5)$ \\
\hline $6-9$ years & $31(29.8)$ & $7(12.3)$ & $17(23.3)$ \\
\hline$>9$ years & $32(30.8)$ & $17(29.8)$ & $25(34.2)$ \\
\hline \multicolumn{4}{|l|}{ Time duration of practicing the sport $(n=234)$} \\
\hline$<5$ hours & $87(83.7)$ & $55(96.5)$ & $64(87.7)$ \\
\hline 5-10 hours & $16(15.3)$ & $2(3.5)$ & 7 (9.6) \\
\hline $10-15$ hours & $1(1)$ & 0 & $2(2.7)$ \\
\hline
\end{tabular}


Table 2: Responses toward dental injuries and type of sports of study subjects

\begin{tabular}{|c|c|c|c|c|}
\hline \multirow[b]{3}{*}{ Questions related to dental injuries } & \multicolumn{3}{|c|}{ Type of sports } & \multirow[b]{3}{*}{$p$-value } \\
\hline & Football $(n=104)$ & Volleyball $(n=57)$ & Taekwondo $(n=73)$ & \\
\hline & $n(\%)$ & $n(\%)$ & $n(\%)$ & \\
\hline \multicolumn{5}{|c|}{$\begin{array}{l}\text { Do you think that dental injuries could happen during sport } \\
\text { practicing? }\end{array}$} \\
\hline Yes & $85(81.7)$ & $48(84.2)$ & $61(83.6)$ & 0.99 \\
\hline No & $12(11.5)$ & $6(10.5)$ & $7(9.6)$ & \\
\hline Don't know & $7(6.8)$ & $3(5.3)$ & $5(6.8)$ & \\
\hline \multicolumn{5}{|c|}{ Have you ever had maxillofacial injuries during sport practicing? } \\
\hline Yes & $59(56.7)$ & $15(26.3)$ & $44(60.3)$ & $<0.0001$ \\
\hline No & $36(34.6)$ & $40(70.2)$ & $23(31.5)$ & \\
\hline Don't know & $9(8.7)$ & $2(3.5)$ & $6(8.2)$ & \\
\hline \multicolumn{5}{|c|}{ Have you ever had a dental injuries during practicing sports? } \\
\hline Yes & $55(52.9)$ & $18(31.6)$ & $41(56.2)$ & 0.056 \\
\hline No & $44(42.3)$ & $34(59.6)$ & $28(38.4)$ & \\
\hline Don't know & $5(4.8)$ & $5(8.8)$ & $4(5.5)$ & \\
\hline If yes, breakage of one of the teeth & $34(32.7)$ & $6(10.5)$ & $11(15.1)$ & 0.001 \\
\hline If yes, mobility of the teeth & $20(19.2)$ & $8(14)$ & $17(23.3)$ & 0.41 \\
\hline If yes, avulsion of one of the teeth & $4(3.8)$ & $4(8.1)$ & $14(19.2)$ & 0.001 \\
\hline \multicolumn{5}{|c|}{$\begin{array}{l}\text { Have you ever had an injury in which maxillofacial and dental } \\
\text { were not included? }\end{array}$} \\
\hline Yes & 64 (61.5) & $28(49.1)$ & $46(63)$ & 0.39 \\
\hline No & $26(25)$ & $22(38.6)$ & $19(26)$ & \\
\hline Don't know & $14(13.5)$ & 7 (12.3) & $8(11)$ & \\
\hline
\end{tabular}

mobility (18\%) were the frequent dental injuries experienced by the athletes (Table 2).

Awareness of mouthguard use during sports practice among taekwondo athletes was found to be significantly higher $(83.6 \%)$ than that in other players $(p<0.0001)$. In general, most athletes $(61.9 \%)$ reported that their coaches were instrumental in educating them, the importance of mouthguards. Practical use of mouthguards during practice was significantly evident in taekwondo athletes (43.8\%) than in others $(p<0.0001)$. It was noted that boil and bit type of mouthguard was popular among the athletes (68.7\%). While $45 \%$ taekwondo and $54 \%$ volleyball players mentioned lack of concern, $50 \%$ football/soccer players mentioned lack of information and advice from coaches to be the reasons for their failure of mouthguard use during sports practice (Table 3 ).

\section{Discussion}

Influence of sports-related dental trauma on subjects irrespective of their age, gender, or skills is reported worldwide. Sportspersons are at an undeniable risk of sustaining dental trauma in organized or unorganized sporting activities at both competitive and recreational levels. The inherent risks of injuries in contact and collision sports, e.g., boxing, are undebatable; however, dental injuries even in no-contact sports, e.g., skating and gymnastics, are not excluded. ${ }^{18-20}$ The athletes comprise a highly susceptible population to dental injuries with $10 \%$ risk of enduring dental and facial trauma during their active season and 33 to $56 \%$ risk of orofacial injury throughout their sports career.
Owing to the scarcity of literature research on sports-related dental trauma in Saudi Arabia, the present study aimed to evaluate the dental trauma prevalence and analyze the utilization of mouthguard in athletes of Riyadh, Saudi Arabia. Based on the interest to assess the effect on contact type, the present study considered (1) taekwondo, a direct contact sport; (2) football/soccer, an indirect contact; and (3) volley ball, a no/minimal contact sport for the study. Additionally, based on the assumption that direct contact and incidence of dental trauma are directly proportional also paved way to consider the above sports to assess and correlate the observations. These sports, being the most popular among the Saudi Arabian population are regularly practiced by licensed athletes.

Correa et al. conducted a study on 38 teams comprising Brazilian professional soccer players. They reported nearly $71.1 \%$ of players with a single dental trauma, while $29.6 \%$ with more than four dental injuries. Crown fractures (74.1\%) and avulsion (59.3\%) were the predominant findings in the study. ${ }^{21}$ The present study findings too are in accordance with crown fracture being the most common dental injury; however, it is followed by tooth mobility instead.

While Keçeci et al. reported dental trauma highest in taekwondo (24\%) players followed by volleyball $(8 \%)$ in the elite Turkey athletes; ${ }^{22}$ Tin-Oo et al. recorded $41.5 \%$ in martial arts, $17.2 \%$ in ball sports, and $15.2 \%$ in no contact sports among Malaysian athletes. ${ }^{23}$ These findings are similar to the present study results; however, the differences in the percentages can be accounted to the variation in sample size among studies.

In volleyball, though contact with the opposing team is limited, contact with similar team members by accident is a possibility. 
Table 3: Responses toward mouthguard and it use and type of sports of study subjects

\begin{tabular}{|c|c|c|c|c|}
\hline \multirow[b]{3}{*}{ Questions related to dental injuries } & \multicolumn{3}{|c|}{ Type of sport } & \multirow[b]{3}{*}{$p$-value } \\
\hline & Football $(n=104)$ & Volleyball $(n=57)$ & Taekwondo $(n=73)$ & \\
\hline & $n(\%)$ & $n(\%)$ & $n(\%)$ & \\
\hline \multicolumn{5}{|c|}{$\begin{array}{l}\text { Are you aware that you can use mouthguard during } \\
\text { sport practice? }\end{array}$} \\
\hline Yes & $33(31.7)$ & $30(52.6)$ & $61(83.6)$ & $<0.001$ \\
\hline No & $71(68.3)$ & $27(47.4)$ & $12(16.4)$ & \\
\hline \multicolumn{5}{|c|}{$\begin{array}{l}\text { Are you aware that using mouthguard could prevent } \\
\text { dental injuries? }\end{array}$} \\
\hline Yes & $32(30.7)$ & $39(68.6)$ & $63(86.3)$ & $<0.001$ \\
\hline No & $72(69.3)$ & $18(31.4)$ & $10(13.7)$ & \\
\hline \multicolumn{5}{|c|}{ If you answer yes on the last question, who told you? } \\
\hline Family & $3(9.4)$ & $4(10.3)$ & $13(20.6)$ & $<0.001$ \\
\hline Coach & $2(6.3)$ & $8(20.5)$ & $39(61.9)$ & \\
\hline Athletic friends & $9(28.1)$ & $8(20.5)$ & $5(7.9)$ & \\
\hline Media & $11(34.4)$ & $12(30.8)$ & $3(4.8)$ & \\
\hline Dentist & $7(21.8)$ & $7(17.9)$ & $3(4.8)$ & \\
\hline \multicolumn{5}{|l|}{ Do you wear mouthguard during sport practice? } \\
\hline Yes & $9(8.7)$ & $7(12.3)$ & $32(43.8)$ & $<0.001$ \\
\hline No & $95(91.3)$ & $50(87.7)$ & $41(56.2)$ & \\
\hline \multicolumn{5}{|c|}{$\begin{array}{l}\text { If your answer yes to the last question, what is the } \\
\text { type of the mouthguard }\end{array}$} \\
\hline Ready made & $3(33.3)$ & $1(14.3)$ & $6(18.8)$ & 0.01 \\
\hline Special made & $5(55.6)$ & $1(14.3)$ & $22(68.7)$ & \\
\hline Fabricated by dentist & $1(11.1)$ & $5(71.4)$ & $4(12.5)$ & \\
\hline \multicolumn{5}{|c|}{$\begin{array}{l}\text { If you answer no to the last question, why do you not } \\
\text { use mouthguard? }\end{array}$} \\
\hline Coach did not tell me & $48(50.5)$ & $10(20.0)$ & $1(2.5)$ & $<0.001$ \\
\hline Difficulty of practicing while using it & $15(15.8)$ & $4(8.0)$ & $6(15.0)$ & \\
\hline Hard to breath while using it & $10(10.5)$ & $2(4.0)$ & $14(35.0)$ & \\
\hline Expensive & $2(2.1)$ & $3(6.0)$ & 0 & \\
\hline How it looks & $2(2.1)$ & $4(8.0)$ & $1(2.5)$ & \\
\hline Doesn't concern me & $18(19.0)$ & $27(54.0)$ & $19(45.0)$ & \\
\hline
\end{tabular}

Contact is undeniable in football in an attempt to score, save, and secure the game. Taekwondo, a form of martial arts, characterized by punching and kicking techniques leads to an inevitable direct contact with an increased risk of dental trauma. Martial arts were classified by the Olympic Committee as the high-risk sports, while handball and volleyball were in moderate-risk sports. ${ }^{15}$ In terms of manifesting dental trauma, the present study showed taekwondo and football/soccer were at greater risk when compared to volleyball.

In the present study, 57.3\% athletes were aware of mouthguard as a protective device. This was in contrast to Keçeci et al., who reported $74.69 \%$ athletes were aware of mouthguard use comprising of taekwondo (90\%), handball (77.42\%), and volleyball players (56\%). ${ }^{22}$ However, the authors did report only $4.32 \%$ of the players using the mouthguard, which is less when compared to the present study with $20.5 \%$ of players using the mouthguard. ${ }^{22}$

Various studies on surveillance of mouthguard users and nonusers have constantly reported significant protection against sports-related orofacial trauma in mouthguard users. It offers a durable and protective surface to allocate and disperse forces on impact, and thus minimize the severity of traumatic injury to the hard or soft oral tissues. A study evaluated the effectiveness of mouthguards in reducing injuries during sports and concluded that the overall risk of injury was1.6 to 1.9 times higher with mouthguard absence than with its use. ${ }^{18} \mathrm{~A}$ similar study by Labella et al. reported college basketball team players wearing custom-made mouthguards had significantly less dental injuries than those who were not thereby emphasizing its importance. ${ }^{24}$

Studies have reported that the boil and bite mouthguards and stock mouthguards were less preferred citing poor or ill-fitting as the reasons, thereby increasing the risk of injuries e.g., concussion, which may be life debilitating and threatening. ${ }^{25,26}$ Custom-made mouthguards are proved to offer better protection than boil and bite type. ${ }^{11}$ Neglecting the effective use of mouthguards among athletes can be linked to its association with difficulty in breathing (35\%). It could be due to its poor or ill-fitting adaptation as reported by $56.2 \%$ taekwondo athletes. Athletes' education on enhancement 
of their knowledge, awareness, and utilization of protective equipment and measures is an important subject in sports dentistry that requires attention and implementation. ${ }^{12}$

Dental practitioners also play a vital role in enforcing the awareness and use of mouthguards among athletes. They are advised to educate them about the risks of orofacial injury and provide guidance on the availability of various types of mouthguards, their protective action, efficacy, costs, and advantages. ${ }^{27}$ The best mouthguards are the ones utilized during sport activities. Though many consider custom-made mouthguards to be the most protective, other mouthguards with good fit and adaptation are equally effective.

The present survey concentrated on four sports club and on selected players. Clinical examination including all types of sports with larger sample size including other provinces would be effective in further analysis on dental trauma, awareness, and use of mouthguards in the athletic population. Further research is encouraged to strengthen the evidence-based effectiveness of the available types of mouthguards and application of intervention programs for reducing the incidence and severity of dental injuries.

\section{Conclusion}

Athletes of contact sports did experience dental trauma, thereby accentuating the importance of a mouthguard. Its use should be encouraged and/or mandated to prevent sports-related injuries. It can be concluded that though Saudi athletes are aware of mouthguard, only few used it, thereby necessitating its implementation to prevent trauma. A combined effort from dentist, coach, and sports physician are required to encourage the use of mouthguards in contact sports.

\section{References}

1. Glendor U. Aetiology and risk factors related to traumatic dental injuries-a review of the literature. Dent Traumatol 2009;25(1):19-31. DOI: 10.1111/j.1600-9657.2008.00694.x

2. Filippi A, von Arx T, Buser D. Externe wurzelresorptionen nach zahntrauma: diagnose, konsequenzen, therapie [External root resorption following tooth trauma: its diagnosis, sequelae and therapy]. Schweiz Monatsschr Zahnmed 2000;110(7):712-729. French, German. PMID: 10974945. Available at: https://www.andreas-filippi. ch/pdfs/fachartikel/swiss-dental-journal/01072000_Externe\%20 Wurzelresorptionen\%20nach\%20Zahntrauma..\%20Diagnose,\%20 Konsequenzen,\%20Therapie.pdf

3. Altun C, Ozen B, Esenlik E, et al. Traumatic injuries to permanent teeth in Turkish children, Ankara. Dent Traumatol 2009;25(3):309-313. DOI: 10.1111/j.1600-9657.2009.00778.x

4. Cetinbaş T, Yildirim G, Sönmez H. The relationship between sports activities and permanent incisor crown fractures in a group of school children aged 7-9 and 11-13 in Ankara, Turkey. Dent Traumatol 2008;24(5):532-536. DOI: 10.1111/j.1600-9657.2008.00647.x

5. Ozbay G, Bakkal M, Abbasoglu Z, et al. Incidence and prevention of traumatic injuries in paediatric handball players in Istanbul, Turkey. Eur Arch Paediatr Dent 2013;14(1):41-45. DOI: 10.1007/s40368-012-0005-4

6. Tulunoglu I, Ozbek M. Oral trauma, mouthguard awareness, and use in two contact sports in Turkey. Dent Traumatol 2006;22(5):242-246. DOI: 10.1111/j.1600-9657.2006.00386.x

7. Cerulli G, Carboni A, Mercurio A, et al. Soccer-related craniomaxillofacial injuries. J Craniofac Surg 2002;13(5):627-630. DOI: 10.1097/00001665-200209000-00006

8. Papakosta V, Koumoura F, Mourouzis C. Maxillofacial injuries sustained during soccer: incidence, severity and risk factors. Dent Traumatol 2008;24(2):193-196. DOI: 10.1111/j.1600-9657.2007.00536.x
9. Flanders RA, Bhat $M$. The incidence of orofacial injuries in sports: a pilot study in Illinois. J Am Dent Assoc 1995;126(4):491-496. DOI: 10.14219/jada.archive.1995.0213

10. Heintz WD. Mouth protectors: a progress report. Bureau of Dental Health Education. J Am Dent Assoc 1968;77(3):632-636. DOI: 10.14219/jada.archive.1968.0267

11. Newsome PR, Tran DC, Cooke MS. The role of the mouthguard in the prevention of sports-related dental injuries: a review Int J Paediatr Dent 2001;11(6):396-404. DOI: 10.1046/j.0960-7439.2001.00304.x

12. Ranalli DN. Sports dentistry and dental traumatology. Dent Traumatol 2002;18(5):231-236. DOI: 10.1034/j.1600-9657.2002.00122.x

13. Al-Majed I, Murray JJ, Maguire A. Prevalence of dental trauma in 5-6- and 12-14-year-old boys in Riyadh, Saudi Arabia. Dent Traumatol 2001;17(4):153-158. DOI: 10.1034/j.1600-9657.2001.170403.x

14. Ferrari $\mathrm{CH}$, Ferreria de Mederios JM. Dental trauma and level of information: mouthguard use in different contact sports. Dent Traumatol 2002;18(3):144-147. DOI: 10.1034/j.1600-9657.2002.00017.x

15. Lang B, Pohl Y, Filippi A. Knowledge and prevention of dental trauma in team handball in Switzerland and Germany. Dent Traumatol 2002;18(6):329-334. DOI: 10.1034/j.1600-9657.2002.00123.x

16. Perunski S, Lang B, Pohl $Y$, et al. Level of information concerning dental injuries and their prevention in Swiss basketball-a survey among players and coaches. Dent Traumatol 2005;21(4):195-200. DOI: 10.1111/j.1600-9657.2005.00310.x

17. Biagi R, Cardarelli F, Butti AC, et al. Sports-related dental injuries: knowledge of first aid and mouthguard use in a sample of Italian children and youngsters. Eur J Paediatr Dent 2010;11(2):66-70. PMID: 20635839. Available at: https://www.ejpd.eu/bibliografia_dettaglio. asp?id $=333$

18. Knapik JJ, Marshall SW, Lee RB, et al. Mouthguards in sport activities: history, physical properties and injury prevention effectiveness. Sports Med 2007;37(2):117-144. DOI: 10.2165/00007256-200737020-00003

19. Kumamoto DP, Maeda Y. A literature review of sports-related orofacial trauma. Gen Dent 2004;52(3):270-280; quiz 281. PMID: 15206262. Available at: http://www.saudident.com/album/data/media/16/A_ literature_review_of_sports-related_orofacial.pdf

20. FasciglioneD, Persic R,PohlY, etal. Dental injuries in inline skating-level of information and prevention. Dent Traumatol 2007;23(3):143-148. DOI: 10.1111/j.1600-9657.2005.00415.x. PMID: 17511835.

21. Correa MB, Schuch HS, Collares K, et al. Survey on the occurrence of dental trauma and preventive strategies among Brazilian professional soccer players. J Appl Oral Sci 2010;18(6):572-576. DOI: 10.1590/s167877572010000600007

22. Keçeci AD, Eroglu E, Baydar ML. Dental trauma incidence and mouthguard use in elite athletes in Turkey. Dent Traumatol 2005;21(2):76-79. DOI: 10.1111/j.1600-9657.2004.00302.x

23. Tin-Oo MM, Razali R. Sport-related oral injuries and mouthguard use among athletes in Kelantan, Malaysia. Arch Orofac Sci 2012;7.1:2127. Available at: http://digitalkelantancollection.umk.edu.my/ koleksikelantan/files/original/d9b690bce2dcbb92bea9a36f8923e5d0. pdf

24. Labella CR, Smith BW, Sigurdsson A. Effect of mouthguards on dental injuries and concussions in college basketball. Med Sci Sports Exerc 2002;34(1):41-44. DOI: 10.1097/00005768-200201000-00007

25. Padilla R, Balikov S. Sports dentistry: coming of age in the ' 90 s. J Calif Dent Assoc 1993;21(4):27-34, 36-37. Available at: https://www.cda. org/Home/Education/CDA-Journal/Journal-Archive

26. Park JB, Shaull KL, Overton B, et al. Improving mouth guards. J Prosthet Dent 1994;72(4):373-380. DOI: 10.1016/0022-3913(94)90556-8

27. American Academy of Pediatric Dentistry Clinical Affairs Committee; American Academy of Pediatric Dentistry Council on Clinical Affairs. Policy on prevention of sports-related orofacial injuries. Pediatr Dent 2005-2006;27(7 Suppl):45. PMID: 16541885. Available at: https://www. aapd.org/media/policies_guidelines/p_sports.pdf 